\section{A Systematic Review of Nutrition Recommendation Systems: With Focus on Technical Aspects}

\author{
Abhari S. ${ }^{\oplus}$, Safdari R. ${ }^{2}$, Azadbakht L. ${ }^{3}$, Lankarani K. B. ${ }^{4 *}$ \\ Niakan Kalhori Sh. R. ${ }^{5}$, Honarvar B. ${ }^{6}$, Abhari Kh. ${ }^{7}$, Ayyoubza- \\ deh S. M. ${ }^{1}$, Karbasi Z. ${ }^{1}$, Zakerabasali S. ${ }^{1}$, Jalilpiran Y. ${ }^{8}$
}

\begin{abstract}
Background: Nutrition informatics has become a novel approach for registered dietitians to practice in this field and make a profit for health care. Recommendation systems considered as an effective technology into aid users to adjust their eating behavior and achieve the goal of healthier food and diet. The purpose of this study is to review nutrition recommendation systems (NRS) and their characteristics for the first time.

Material and Methods: The systematic review was conducted using a comprehensive selection of scientific databases as reference sources, allowing access to diverse publications in the field. The process of articles selection was based on the PRISMA strategy. We identified keywords from our initial research, MeSH database and expert's opinion. Databases of PubMed, Web of Sciences, Scopus, Embase, and IEEE were searched. After evaluating, they obtained records from databases by two independent reviewers and inclusion and exclusion criteria were applied to each retrieved work to select those of interest. Finally, 25 studies were included.
\end{abstract}

Results: Hybrid recommender systems and knowledge-based recommender systems with $40 \%$ and $32 \%$, respectively, were the mostly recommender types used in NRS. In NRS, rule-based and ontology techniques were used frequently. The frequented platform that applied in NRS was a mobile application with $28 \%$.

Conclusion: If NRS was properly designed, implemented and finally evaluated, it could be used as an effective tool to improve nutrition and promote a healthy lifestyle. This study can help to inform specialists in the nutrition informatics domain, which was necessary to design and develop NRS.

Citation: Abhari S, Safdari R, Azadbakht L, Lankarani K. B, Niakan Kalhori Sh. R, Honarvar B, Abhari Kh, Ayyoubzadeh S. M, Karbasi Z, Zakerabasali S, Jalilpiran Y. A Systematic Review of Nutrition Recommendation Systems: With Focus on Technical Aspects. J Biomed Phys Eng. 2019;9(6):591-602. https://doi.org/10.31661/jbpe.v0i0.1248.

Keywords

Nutrition; Diet; Information Science; Informatics; Computing Methodologies

\section{Introduction}

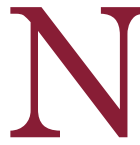

utrition is the essential basis for health and development of human life from the earliest stage of fetal development into old age. Healthy food and proper nutrition are indubitable requirements for survival, physical development, mental growth, performance and productivity, health, and well-being [1-5].

The combination of information technology (IT), information sci-
${ }^{1} \mathrm{PhD}$ Candidate, Health

Information Management

Department, School of

Allied Medical Sciences,

Tehran University of Medi-

cal Sciences, Tehran, Iran

${ }^{2} \mathrm{PhD}$, Professor, Health

Information Management

Department, School of

Allied Medical Sciences,

Tehran University of Medi-

cal Sciences, Tehran, Iran

${ }^{3} \mathrm{PhD}$, Professor, Depart-

ment of Community Nutri-

tion, School of Nutritional

Sciences and Dietetics,

Tehran University of Medi-

cal Sciences, Tehran, Iran

${ }^{4} \mathrm{MD}$, Professor, Health

Policy Research Center.

Institute of Health, Shiraz

University of Medical Sci-

ences, Shiraz, Iran

${ }^{5} \mathrm{PhD}$, Associate Profes-

sor, Health Information

Management Department,

School of Allied Medical

Sciences, Tehran Univer-

sity of Medical Sciences,

Tehran, Iran

${ }^{6} \mathrm{MD}$, Associate Professor

Health Policy Research

Center, Institute of Health,

Shiraz University of Medical

Sciences, Shiraz, Iran

${ }^{7} \mathrm{PhD}$, Department of Food

Science and Technology,

National Nutrition and

Food Technology Research

Institute, Faculty of Nutri-

tion Sciences and Food

Technology, Shahid Be-

heshti University of Medica

Sciences, Tehran, Iran

${ }^{8} \mathrm{PhD}$ student, Department

of Clinical Nutrition, School

of Nutritional Sciences and

Dietetics, Tehran Univer-

sity of Medical Sciences,

Tehran, Iran

*Corresponding author:

K. B. Lankarani

Health Policy Research

Center, Institute of

Health, Shiraz University

of Medical Sciences,

Shiraz, Iran

E-mail: kblankarani@

gmail.com

Received: 5 September 2019

Accepted: 28 September 2019 
ences and nutrition has generated the concept of nutrition informatics. This branch of health informatics has become a novel approach for registered dietitians and dietetic technicians to practice in this field and make a profit for health care. The first scientific use of term 'nutrition informatics' referred to 1996; however, the dietitians have been applying the nutrition information and assuming technology for decades. The first paper exhibiting the potential usage of the computer to analyze dietary intake was published in 1962. Health care has included IT to establish patient care by the use of electronic health records, gather population data through the collection of personal health records and support clinical research via the reuse of data. Moreover, dietitians have involved particular electronic tools developed for managing patient tray service, indexing, and evaluation of nutrients [6-17].

Though most people have been informed about the significance of healthy eating habits, they incline to neglect suitable behaviors because of urban lifestyle and/or unwillingness to spend cognitive attempt on food provision. Those barriers prevent people from healthy food intake [18-20]. Nutrition recommendation systems (NRS) are one of the main technologies applyed in nutrition informatics scope. They are explored as an effective tool in order to support users for changing their eating behavior and reaching the goal of healthier food choices. NRS not only recommends users' preferences for food, but also recommends healthy diet choices; in addition, it can advise appropriate diet and keep pursue of eating behavior, realize health problems, and lead into alteration user behavior [21-24] .

Generally, recommendation systems have developed an efficient and effective technology to extract valuable information and then use it in an effectual way. A recommender system can predict the preferences of users for unrated items and recommend new items to users. The capability of these systems depends on technical requirements and proper design based on system types and functionality. Several various techniques have been proposed for developing personalized recommendations; these varieties in applied techniques and design may create various types of recommendation systems, including collaborative filtering recommender systems (CF), content-based recommender systems (CB), knowledge-based recommender systems (KBS) and hybrid recommender systems (HRS) [21, 24-28].

There has been no detailed investigation to review NRS and their characteristics. The purpose of this study is to review recommendation systems in the nutrition field with focus on characteristics, types and evaluation methods. Moreover, this study uses a systematic review approach based on PRISMA guideline.

This systematic review responds to the following research questions:

RQ1: Which types of recommendation systems are mostly used in the field of nutrition?

RQ2: Which Artificial Intelligence (AI) techniques or intelligent methods are applied in NRS?

RQ3: What are the main modules of these NRS?

RQ4: Which platforms design NRS?

\section{Material and Methods}

This systematic review was conducted based on the preferred reporting items for systematic reviews and meta-analysis (PRISMA). Figure 1 displays the process of PRISMA for data collection and analysis.

\section{Search strategy}

The papers from PubMed, Scopus, Embase, Web of Science, IEEE (Institute of Electrical and Electronics Engineers) and Google Scholar databases were searched without time limitation (up 10 January 2019).

The PICO (population, intervention, comparison, and outcome) criteria were used to define the search string: population $(\mathrm{P})$, intervention (I), comparison (C), and outcome (O). The population was defined based on whom 


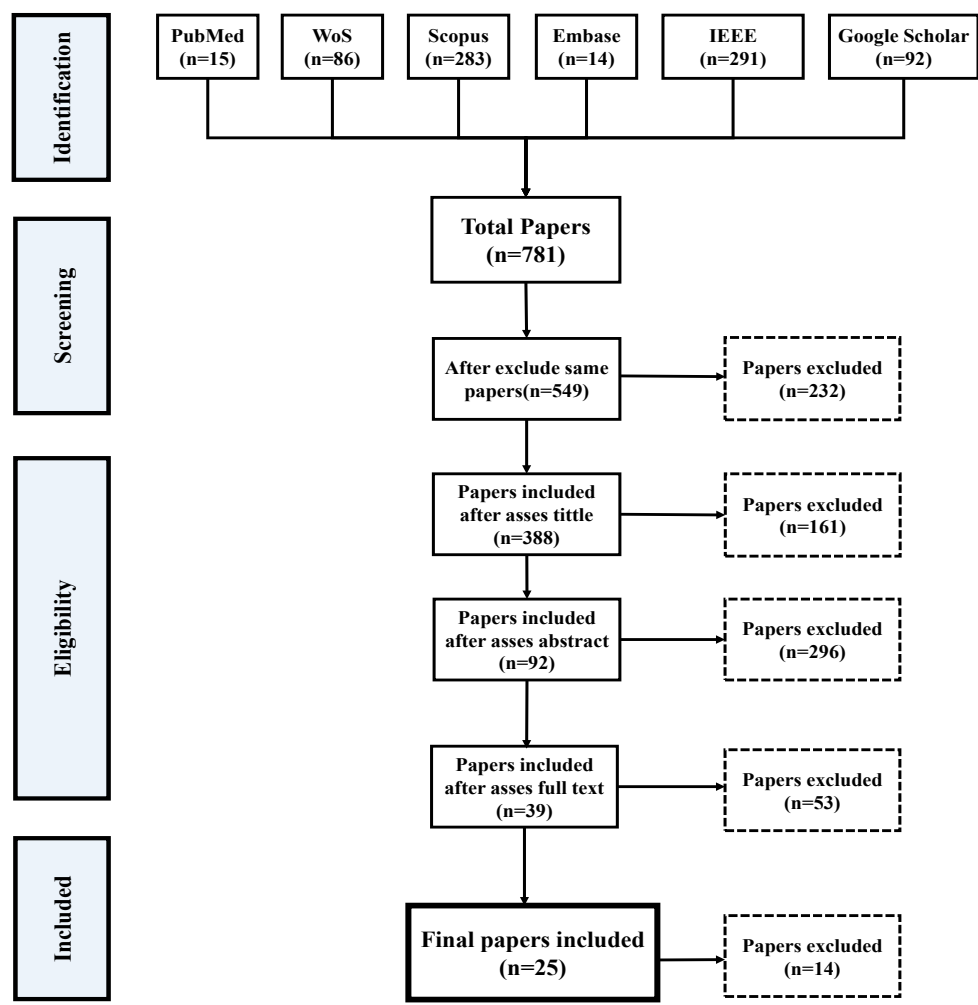

Figure 1: Process of PRISMA for data collection and analysis

systems were designed for. The intervention was the usage of recommendation systems in the nutrition field. The comparison was excluded and the outcomes were the characteristics and types of developed NRS as well as their methods of evaluation.

We identified keywords from our initial research and matched them with those existing on the database of Medical Subject Headings $(\mathrm{MeSH})$, which is managed by the US National Library of Medicine. In addition, we used an expert working in the medical branch libraries to improve the quality of searches. The search strings based on MeSH and title, abstract and keywords were as follows: (nutrition* OR diet OR food* OR meal) and (recommend* system*).

\section{Inclusion and exclusion criteria}

The inclusion criteria were original articles and proceedings. Moreover, just articles which focus on NRS and have health-promotion goals, and papers up 10 January 2019 were included. Exclusion criteria were NonEnglish papers, any types of publication other than journal articles and proceedings (review papers, letters, etc.), and non-human study papers. Furthermore, papers focusing on systems other than recommendation systems such as expert, clinical decision support systems and those only working with business and marketing purposes were excluded.

\section{Selection process}

In the primary screening, two individual reviewers screened titles and abstracts of the articles based on the research and PICO questions and the papers were classified into three sets completely. The first set (number 1) contained the papers with certainly inclusion criteria. The next set (number 2) contained the papers that their inclusion criteria were not 
clear for reviewers. Lastly, set (number 0) referred to the papers with no inclusion criteria, which were ineligible and excluded from the screening. The reviewers assessed the papers with different assigned numbers and discussed them. All the papers with similar numbers (one or two) were involved for the next stage. Following, the full text of the involved papers was achieved for the second-stage of screening and then evaluated by two reviewers. Finally, we were certain about 25 papers, then summarized and reported them in tables and charts according to the aims of the study.

\section{Data extraction}

In this phase, 6 variables were extracted in order to response to the research questions. These variables contained the name of the system, type of recommendation system, artificial intelligence (AI) or intelligent techniques applied in recommendation system, system modules and type of system's platform.

\section{Results}

Table 1 shows data extracted from the 25 articles reviewed [23, 29-52]. The sixth variables of the selected papers are presented in Table 1 .

\section{Type of recommendation system}

As presented in the fourth column of Table 1 , the types of recommendation system were studied. The frequency (\%) of recommendation system types is presented in Figure 2.

\section{AI or intelligent techniques apply in recommendation systems}

As shown in the fifth column of Table 1, various AI or intelligent techniques have been applied in recommendation systems. The types of these techniques with their frequency in the researches are stated in Figure 3.

The seventh column of Table 1 illustrates the type of system's platform. Figure 4 demonstrates the frequency of the type of system's platform. Based on the chart, the frequented platform applied in NRS was a mobile application with $28 \%$.

\section{Discussion}

Despite the various application of recommendation systems in many domains, there is not much evidence for using recommendation systems in health informatics or medicine [53]. According to the Valdez framework [53], if we want to design or assess the health recommender system, it will be necessary to consider 3 main aspects. First of all, we should understand the health domain. In this aspect, answering these two questions is very important: 1) which one of following items is recommended (nutrition, medicine, sport)? In addition, 2) who is it recommended to (the patient, the doctor, the nurse, policy maker)?

Another aspect that should be considered is the understanding of technical specifications and data analysis methods used in health recommendation system. The third aspect that needs to be addressed in the analysis of health recommendation system is the understanding of the methods and techniques of evaluating recommender systems. Besides, this paper for the first time reviewed the technical specifications of NRS.

The items in the results have been discussed in the following:

\section{Type of recommendation systems}

Hybrid recommender systems (HRS) are the mostly used recommender type in nutrition recommendation systems (Figure 2). As these systems use a combination of other systems type, they could compensate disadvantages of one type of recommendation system by another type. Moreover, hybrid types are applied in order to increase the recommender's performance $[21,25]$.

AI or intelligent techniques applied in recommendation systems

In NRS, rule-based techniques are frequently used (Figure 3). The reason behind that might 


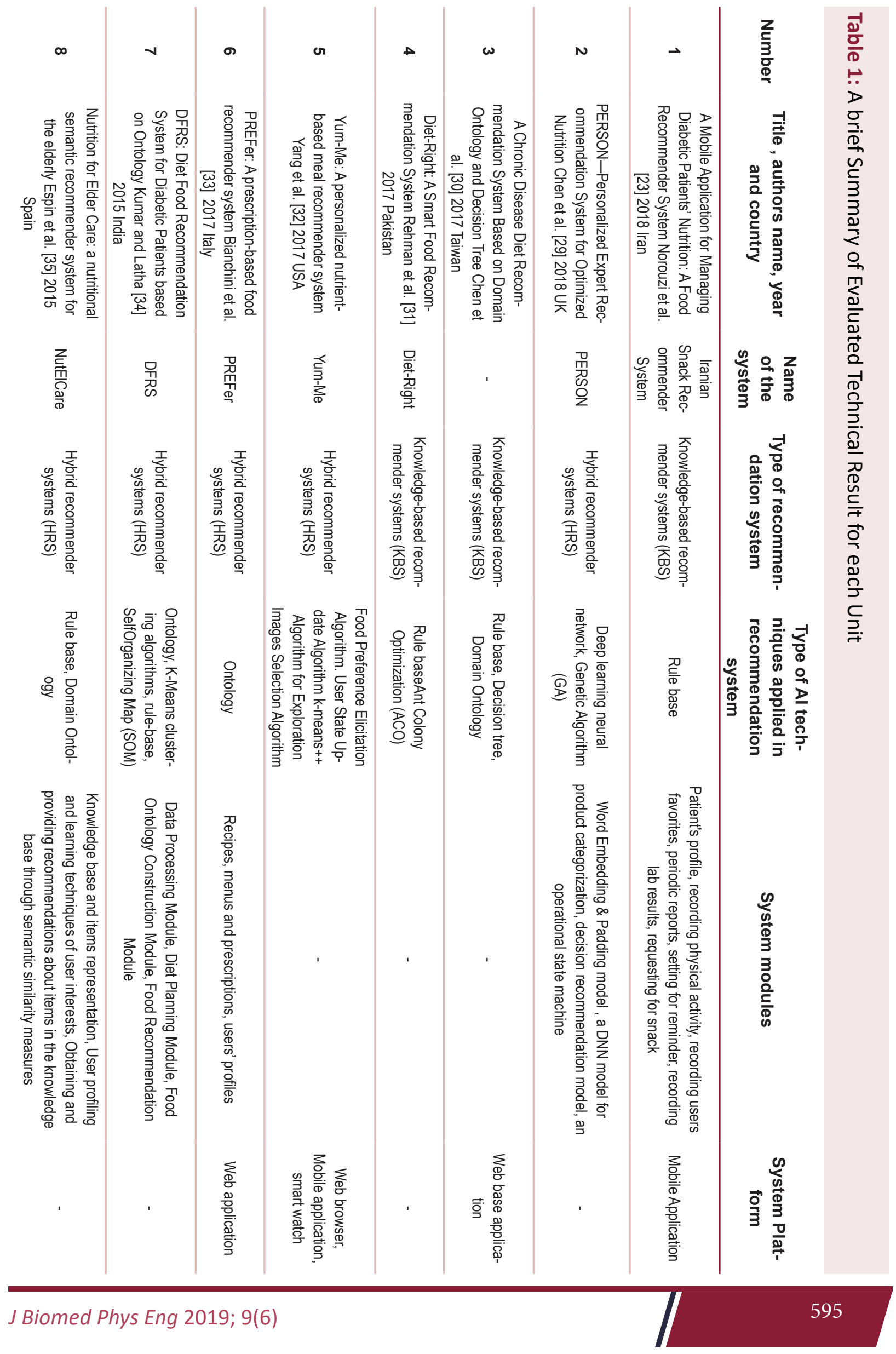




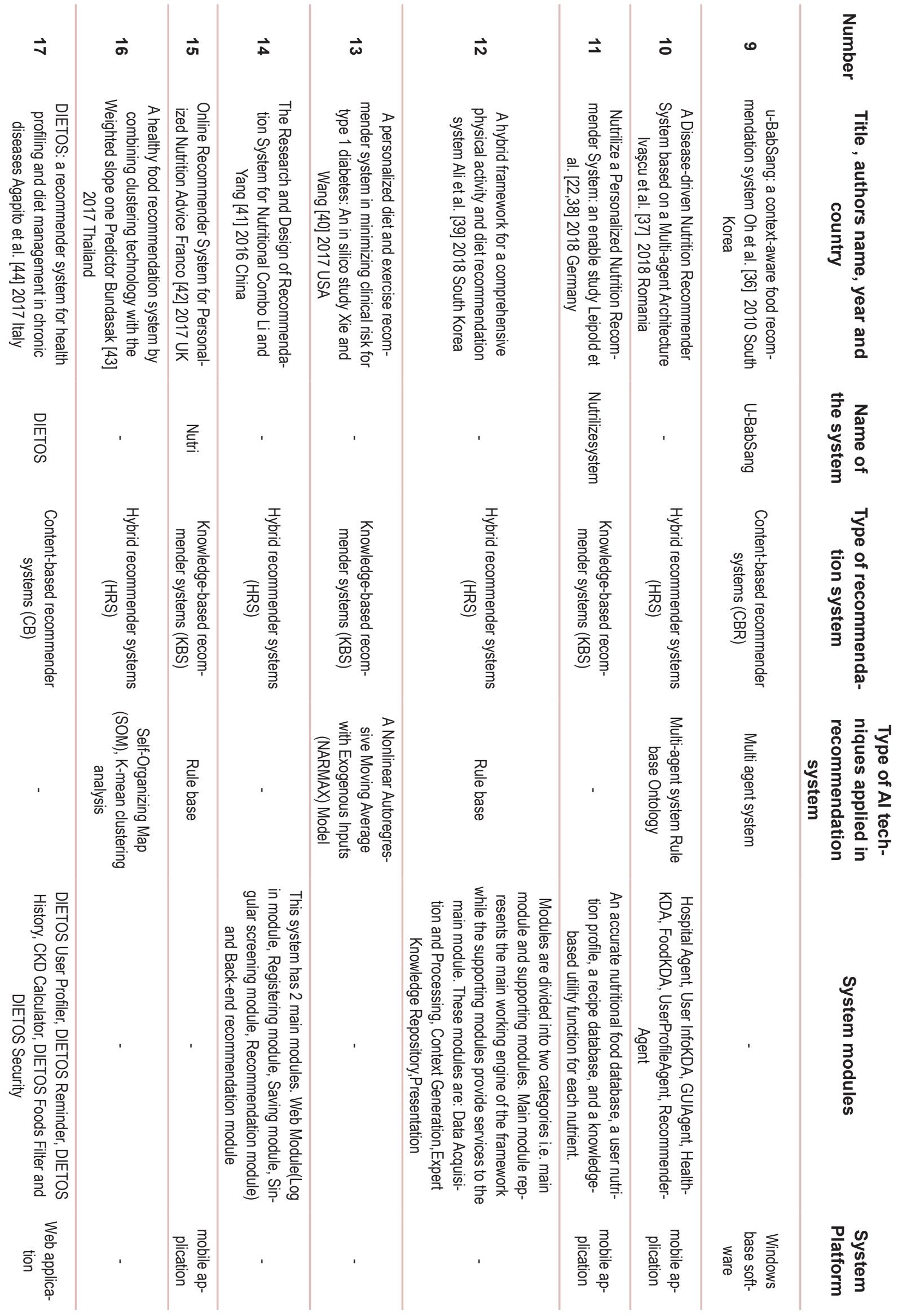




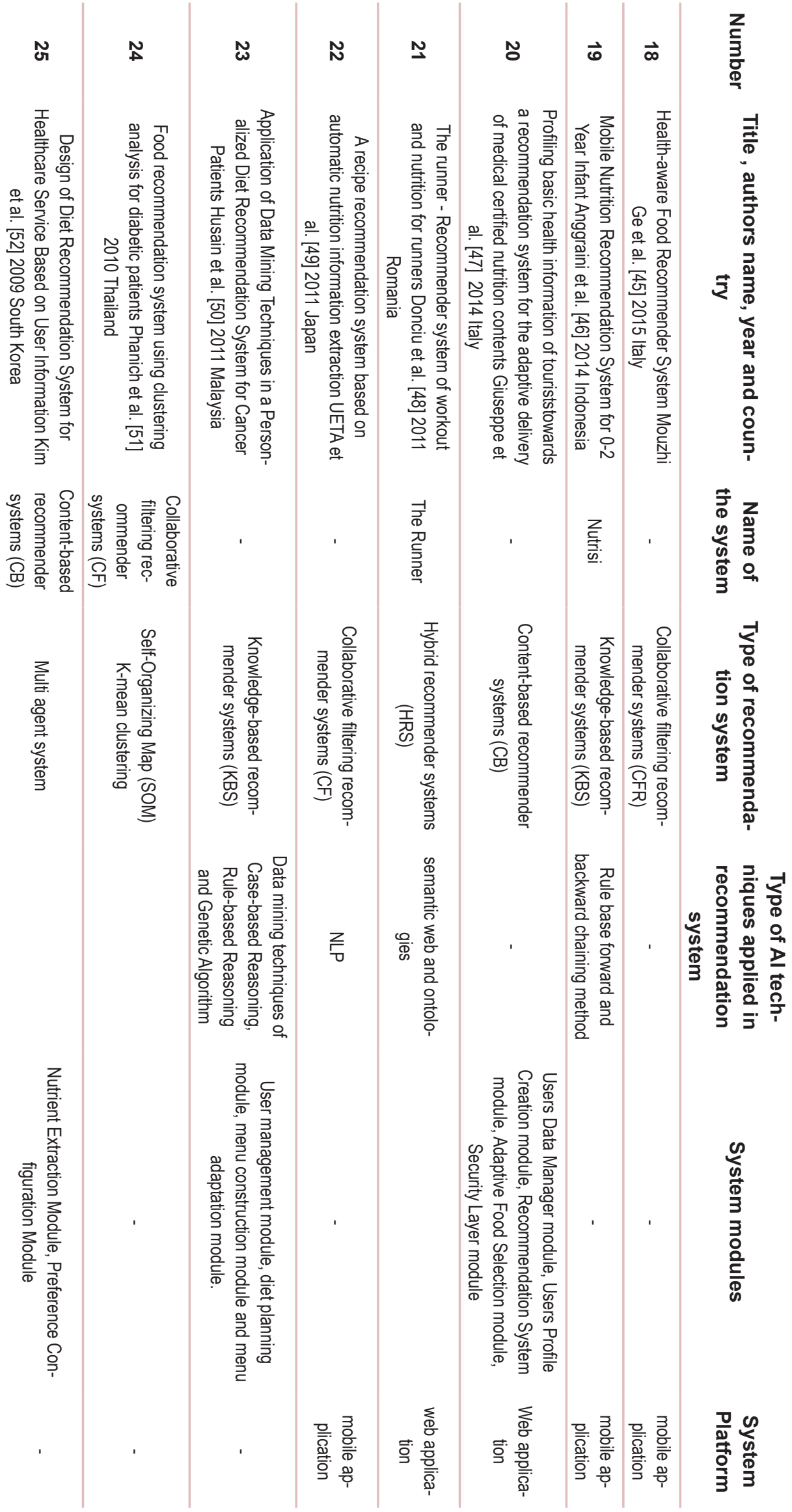




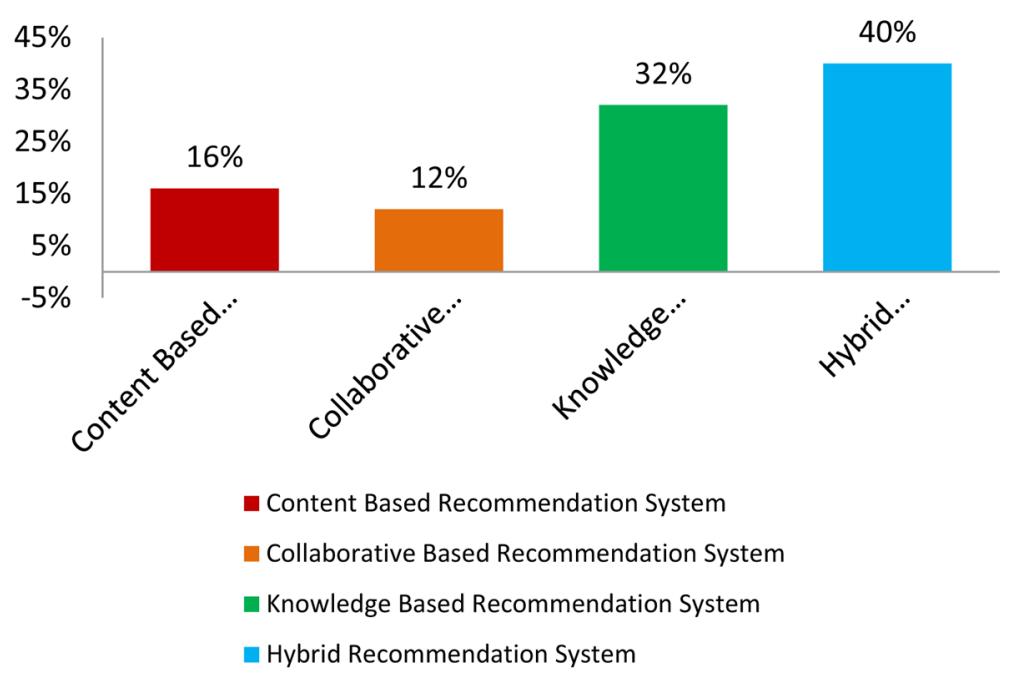

Figure 2: The frequency (\%) of recommendation system types

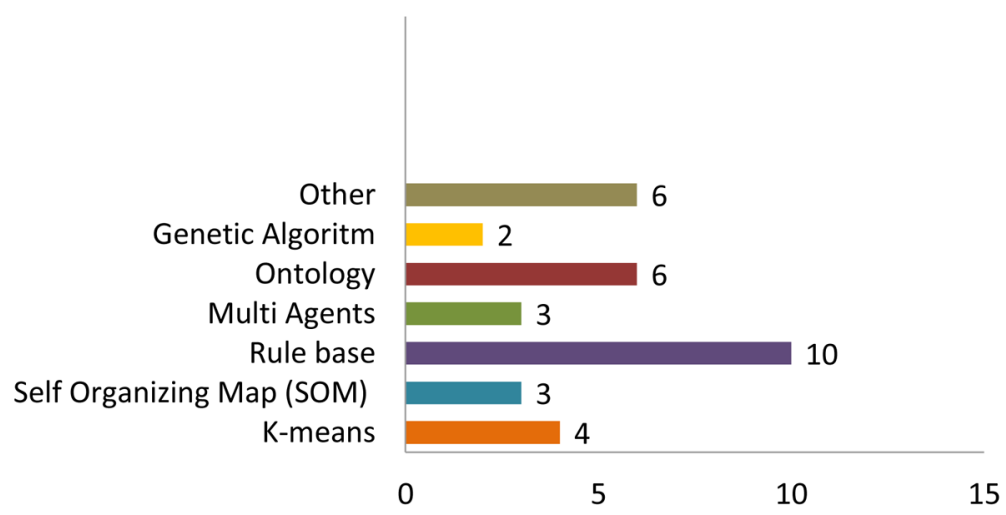

Figure 3: Frequncy of Al or intelligent techniques applied in recommendation systems

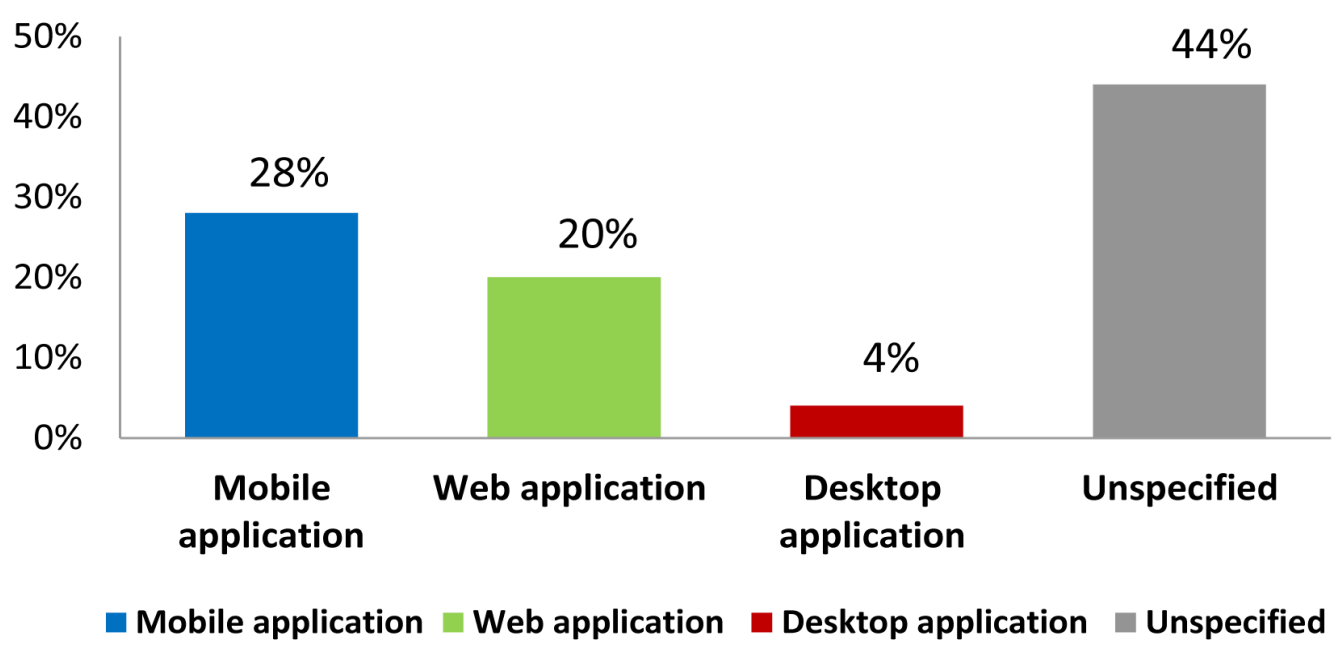

Figure 4: Frequncy of type of system's platform 
be the simplicity, transparency, and consistency of rule-based techniques with nutrition knowledge. Ontology techniques also have been used for the same reasons to show the knowledge and concepts of relations in a clear manner.

Cold start, which is one of the classic problems in recommendation systems, happens when a new user uses the system with no preferences [54]. Although this situation seems to not occur frequently in NRS, recommendation of collaborative filtering, which is contentbased, is made by [41] to overcome this issue.

\section{Type of system's platform and their structure}

Owing to the penetration of smartphones, their processing, connectivity capabilities and their accessibility [55, 56], mobile applications had a growth in the medical field [56]. As it has been shown that mobile apps have potential effects on health behavior change [57] and chronic disease management [58], they have been used in the most of reviewed systems for NRS as shown in Figure 4.

In addition, web technology, due to its crossplatform specificity leading into the use of multiple clients with different hardware and operating system, is popular for these recommendation systems.

This is the first systematically review of the recommendation systems in the nutrition field with focus on characteristics and types. The study offers some important insights into the condition of recommendation systems in the nutrition field with focus on technical aspects. This study can help to inform specialists in the nutrition informatics domain, which was necessary to design and develop NRS.

However, there are many mobile applications in the nutrition field useing "recommendation system" technology which have not been mentioned in the design methodology [57]. This study concentrates only on research, which explicitly discusses the use of the recommendation system.

\section{Conclusion}

In this paper, we systematically reviewed the recommender systems in nutrition scope with a focus on characteristics and types. The results of this investigation show that hybrid recommender systems (HRS) are mostly used recommender type in NRS. Many AI or intelligent techniques applied in recommendation systems, which are one of the most frequented techniques, are systems based on rules. Furthermore, the frequented platform applied in NRS was a mobile application. If NRS is properly designed, implemented, and finally evaluated, it can be used as an effective tool to improve nutrition and promote a healthy lifestyle.

\section{Acknowledgment}

The authors would like to gratefully acknowledge the contribution department of health information management and department of community nutrition in Tehran University of Medical Sciences. This paper was developed as part of a Ph.D. thesis that is funded and supported jointly by Tehran University of Medical Sciences and Shiraz University of Medical Sciences.

\section{Conflict of Interest}

The authors declare that there is no conflict of interest regarding the publication of this manuscript.

\section{References}

1. Cederholm T, Barazzoni R, Austin $P$, Ballmer $P$, Biolo G, Bischoff SC, et al. ESPEN guidelines on definitions and terminology of clinical nutrition. Clin Nutr. 2017;36:49-64. doi: 10.1016/j. clnu.2016.09.004. PubMed PMID: 27642056.

2. Organization WH. Diet, nutrition and the prevention of chronic diseases. World Health Organ Tech Rep Ser. 2003;916:1-149. PubMed PMID: 12768890.

3. Organization WH. Diet, nutrition, and the prevention of chronic diseases. Report of a WHO Study Group. World Health Organ Tech Rep Ser. 1990;797:1-204. PubMed PMID: 2124402.

4. Resilience B. The State Of Food Security And Nutrition In The World. Rome: Building resilience for 
peace and food security; 2017.

5. Thompson B, Cohen MJ, Meerman J. World food insecurity and malnutrition: scope, trends, causes and consequences. The impact of climate change and bioenergy on nutrition: Springer; 2012. p. 2141. doi: 10.1007/978-94-007-0110-6_3.

6. North JC, Jordan KC, Metos J, Hurdle JF. Nutrition Informatics Applications in Clinical Practice: a Systematic Review. AMIA Annu Symp Proc. 2015;2015:963-72. PubMed PMID: 26958233; PubMed PMCID: PMCPMC4765562.

7. Ayres EJ, Greer-Carney JL, Fatzinger McShane PE, Miller A, Turner P. Nutrition informatics competencies across all levels of practice: a national Delphi study. J Acad Nutr Diet. 2012;112:2042-53 doi: 10.1016/j.jand.2012.09.025. PubMed PMID: 23174690; PubMed PMCID: PMCPMC3652246.

8. Bernstam EV, Smith JW, Johnson TR. What is biomedical informatics? J Biomed Inform. 2010;43:104-10. doi: 10.1016/j.jbi.2009.08.006. PubMed PMID: 19683067; PubMed PMCID: PMCPMC2814957.

9. Trtovac D, Lee J. The Use of Technology in Identifying Hospital Malnutrition: Scoping Review. JMIR Med Inform. 2018;6:e4. doi: 10.2196/medinform.7601. PubMed PMID: 29351894; PubMed PMCID: PMCPMC5797288.

10. Ayres EJ, Hoggle LB. 2011 nutrition informatics member survey. J Acad Nutr Diet. 2012;112:3607. doi: 10.1016/j.jand.2012.01.003. PubMed PMID: 22709663; PubMed PMCID: PMCPMC3640305.

11. Hoggle LB, Michael MA, Houston SM, Ayres EJ. Nutrition informatics. J Am Diet Assoc. 2006;106:134-9. doi: 10.1016/j.jada.2005.10.025. PubMed PMID: 16390678.

12. Ayres EJ, Hoggle LB. Advancing practice: using nutrition information and technology to improve health-the nutrition informatics global challenge. Nutrition \& Dietetics. 2012;69:195-7. doi: 10.1111/j.1747-0080.2012.01616.x.

13. Kuo SE, Lai HS, Hsu JM, Yu YC, Zheng DZ, Hou TW. A clinical nutritional information system with personalized nutrition assessment. Comput Methods Programs Biomed. 2018;155:209-16. doi: 10.1016/j.cmpb.2017.10.029. PubMed PMID: 29512501.

14. Buday R, Tapia R, Maze GR. Technology-driven dietary assessment: a software developer's perspective. J Hum Nutr Diet. 2014;27(Suppl 1):107. doi: 10.1111/j.1365-277X.2012.01255.x. PubMed PMID: 22591224; PubMed PMCID: PMCPMC4365297.
15. Kirk SF, Cade JE, Greenhalgh A. Dietitians and the internet: are dietitians embracing the new technology? J Hum Nutr Diet. 2001;14:477-84. doi: 10.1046/j.1365-277x.2001.00314.x. PubMed PMID: 11906590.

16. Roberts S, Marshall AP, Gonzalez R, Chaboyer W. Technology to engage hospitalised patients in their nutrition care: a qualitative study of usability and patient perceptions of an electronic foodservice system. J Hum Nutr Diet. 2017;30:563-73. doi: 10.1111/jhn.12467. PubMed PMID: 28211190.

17. Maunder K, Walton K, Williams P, Ferguson M, Beck E. eHealth readiness of dietitians. J Hum Nutr Diet. 2018;31:573-83. doi: 10.1111/jhn.12542. PubMed PMID: 29473238.

18. Deshpande S, Basil MD, Basil DZ. Factors influencing healthy eating habits among college students: an application of the health belief model. Health Mark Q. 2009;26:145-64. doi: 10.1080/07359680802619834. PubMed PMID: 19408181.

19. Schwartz C, Scholtens PA, Lalanne A, Weenen H, Nicklaus S. Development of healthy eating habits early in life. Review of recent evidence and selected guidelines. Appetite. 2011;57:796-807. doi: 10.1016/j.appet.2011.05.316. PubMed PMID: 21651929.

20. Crovetto $M$, Valladares $M$, Espinoza V, Mena $F$, Onate $G$, Fernandez $M$, et al. Effect of healthy and unhealthy habits on obesity: a multicentric study. Nutrition. 2018;54:7-11. doi: 10.1016/j. nut.2018.02.003. PubMed PMID: 29677480.

21. Tran TNT, Atas M, Felfernig A, Stettinger M. An overview of recommender systems in the healthy food domain. Journal of Intelligent Information Systems. 2018;50:501-26. doi: 10.1007/s10844017-0469-0.

22. Leipold $N$, Madenach $M$, Schäfer $H$, Lurz $M$, Terzimehic N, Groh G, et al., editors. Nutrilize a Personalized Nutrition Recommender System: an Enable Study. Healt hRecSys@ RecSys; 2018.

23. Norouzi $S$, Kamel Ghalibaf A, Sistani S, Banazadeh V, Keykhaei F, Zareishargh P, et al. A Mobile Application for Managing Diabetic Patients' Nutrition: A Food Recommender System. Arch Iran Med. 2018;21:466-72. PubMed PMID: 30415555.

24. Norouzi S, Nematy M, Zabolinezhad H, Sistani S, Etminani K. Food recommender systems for diabetic patients: a narrative review. Rev Clin Med. 2017;4(3):128-30. doi: 10.22038/ rcm.2017.10814.1134. 
25. Ricci F, Rokach L, Shapira B. Introduction to recommender systems handbook. Recommender systems handbook: Springer; 2011. p. 1-35. doi: 10.1007/978-0-387-85820-3_1.

26. Park DH, Kim HK, Choi IY, Kim JK. A literature review and classification of recommender systems research. Expert systems with applications. 2012;39:10059-72. doi: 10.1016/j. eswa.2012.02.038.

27. Robillard M, Walker R, Zimmermann T. Recommendation systems for software engineering. IEEE software. 2009;27:80-6.

28. Shani G, Gunawardana A. Evaluating recommendation systems. Recommender systems handbook: Springer; 2011. p. 257-97. doi: 10.1007/978-0387-85820-3_8.

29. Chen $\mathrm{CH}$, Karvela $M$, Sohbati $M$, Shinawatra $T$, Toumazou C. PERSON-Personalized Expert Recommendation System for Optimized Nutrition. IEEE Trans Biomed Circuits Syst. 2018;12:15160. doi: 10.1109/TBCAS.2017.2760504. PubMed PMID: 29377803.

30. Chen R-C, Huang C-Y, Ting Y-H. A chronic disease diet recommendation system based on domain ontology and decision tree. Journal of Advanced Computational Intelligence and Intelligent Informatics. 2017;21:474-82. doi: 10.20965/jaciii.2017. p0474.

31. Rehman F, Khalid O, Bilal K, Madani SA. Diet-Right: A Smart Food Recommendation System. KSII Transactions on Internet \& Information Systems. 2017;11. doi: 10.3837/tiis.2017.06.006.

32. Yang L, Hsieh CK, Yang H, Pollak JP, Dell N, Belongie S, et al. Yum-Me: A Personalized Nutrient-Based Meal Recommender System. ACM Trans Inf Syst. 2017;36. doi: 10.1145/3072614. PubMed PMID: 30464375; PubMed PMCID: PMCPMC6242282.

33. Bianchini D, De Antonellis V, De Franceschi N, Melchiori M. PREFer: A prescription-based food recommender system. Computer Standards \& Interfaces. 2017;54:64-75. doi: 10.1016/j.csi.2016.10.010.

34. Raj Kumar B, Latha K. DFRS: Diet food recommendation system for diabetic patients based on ontology. Int J Appl Eng Res. 2015;10:2765-70.

35. Espín V, Hurtado MV, Noguera M. Nutrition for Elder Care: a nutritional semantic recommender system for the elderly. Expert Systems. 2016;33:20110. doi: 10.1111/exsy.12143.

36. Oh Y, Choi A, Woo W. u-BabSang: a contextaware food recommendation system. the Journal of Supercomputing. 2010;54:61-81. doi: 10.1007/ s11227-009-0314-5.
37. Ivaşcu T, Diniş A, Cincar K, editors. A Diseasedriven Nutrition Recommender System based on a Multi-agent Architecture. Proceedings of the 8th International Conference on Web Intelligence, Mining and Semantics; New York: ACM; 2018. doi: 10.1145/3227609.3227685.

38. Terzimehić N, Leipold N, Schaefer $H$, Madenach M, Böhm M, Groh G, et al. Can an Automated Personalized Nutrition Assistance System Successfully Change Nutrition Behavior?-Study Design. International Conference on Information Systems (ICIS); At Dublin: Ireland; 2016.

39. Ali SI, Amin MB, Kim S, Lee S, editors. A Hybrid Framework for a Comprehensive Physical Activity and Diet Recommendation System. International Conference on Smart Homes and Health Telematics; Springer; 2018.

40. Xie J, Wang Q. A personalized diet and exercise recommender system for type 1 diabetes self-management: $A n$ in silico study. Smart Health. 2019;13:100069. doi: 10.1016/j. smhl.2019.100069.

41. Li C, Yang C, editors. The research and design of recommendation system for nutritional combo. 2016 2nd IEEE International Conference on Computer and Communications (ICCC); Chengdu, China: IEEE; 2016. doi: 10.1109/compcomm.2016.7924819.

42. Zenun Franco $\mathrm{R}$, editor Online Recommender System for Personalized Nutrition Advice. Proceedings of the Eleventh ACM Conference on Recommender Systems; New York: ACM; 2017. doi: 10.1145/3109859.3109862.

43. Bundasak $S$, editor A healthy food recommendation system by combining clustering technology with the weighted slope one predictor. 2017 International Electrical Engineering Congress (iEECON); Pattaya, Thailand: IEEE; 2017. doi: 10.1109/ ieecon.2017.8075820.

44. Agapito G, Simeoni M, Calabrese B, Guzzi PH, Fuiano G, Cannataro M, editors. DIETOS: A Recommender System for Health Profiling and Diet Management in Chronic Diseases. HealthRecSys@ RecSys; 2017.

45. Ge M, Ricci F, Massimo D, editors. Health-aware food recommender system. Proceedings of the 9th ACM Conference on Recommender Systems; Vienna Austria: ACM; 2015.

46. Anggraini RNE, Rochimah S, Dalmi KD, editors. Mobile nutrition recommendation system for $0-2$ year infant. 2014 The 1st International Conference on Information Technology, Computer, and Electri- 
cal Engineering; Semarang, Indonesia:Semarang, Indonesia: IEEE; 2014. doi: 10.1109/icitacee.2014.7065755.

47. Agapito G, Calabrese B, Care I, Falcone D, Guzzi $\mathrm{PH}$, lelpo $\mathrm{N}$, et al., editors. Profiling basic health information of tourists: towards a recommendation system for the adaptive delivery of medical certified nutrition contents. 2014 International Conference on High Performance Computing \& Simulation (HPCS); Bologna, Italy: IEEE; 2014. doi: 10.1109/hpcsim.2014.6903744.

48. Donciu M, Ionita M, Dascalu M, Trausan-Matu S, editors. The Runner--Recommender System of Workout and Nutrition for Runners. 2011 13th international symposium on symbolic and numeric algorithms for scientific computing; Timisoara, Romania: IEEE; 2011. doi: 10.1109/synasc.2011.18.

49. Ueta $\mathrm{T}$, Iwakami M, Ito $\mathrm{T}$, editors. A recipe recommendation system based on automatic nutrition information extraction. International Conference on Knowledge Science, Engineering and Management; Springer-Verlag Berlin Heidelberg; 2011. P. 79-90. doi: 10.1109/taai.2011.39.

50. Husain W, Wei LJ, Cheng SL, Zakaria N, editors. Application of data mining techniques in a personalized diet recommendation system for cancer patients. 2011 IEEE Colloquium on Humanities, Science and Engineering; Penang, Malaysia: IEEE; 2011. doi: 10.1109/chuser.2011.6163724.

51. Phanich M, Pholkul P, Phimoltares S, editors. Food recommendation system using clustering analysis for diabetic patients. 2010 International Conference on Information Science and Applications; Seoul, South Korea: IEEE; 2010. doi: 10.1109/ icisa.2010.5480416.

52. Kim J-H, Lee J-H, Park J-S, Lee Y-H, Rim K-W, editors. Design of diet recommendation system for healthcare service based on user information. 2009 Fourth International Conference on Computer Sciences and Convergence Information Technology; Seoul, South Korea; IEEE; 2009. doi: 10.1109/ iccit.2009.293.

53. Valdez AC, Ziefle M, Verbert K, Felfernig A, Holzinger $A$. Recommender systems for health informatics: state-of-the-art and future perspectives. Machine Learning for Health Informatics: Springer; 2016. p. 391-414. doi: 10.1007/978-3-319-504780_20.

54. Lam XN, Vu T, Le TD, Duong AD, editors. Addressing cold-start problem in recommendation systems. Proceedings of the 2nd international conference on Ubiquitous information management and communication; New York: ACM; 2008.

55. Kakihara M, editor Grasping a Global View of Smartphone Diffusion: An Analysis from a Global Smartphone Study. ICMB; 2014.

56. Wiechmann W, Kwan D, Bokarius A, Toohey SL. There's an App for That? Highlighting the Difficulty in Finding Clinically Relevant Smartphone Applications. West J Emerg Med. 2016;17:191-4. doi: 10.5811/westjem.2015.12.28781. PubMed PMID: 26973750; PubMed PMCID: PMCPMC4786244.

57. Zhao J, Freeman B, Li M. Can Mobile Phone Apps Influence People's Health Behavior Change? An Evidence Review. J Med Internet Res. 2016;18:e287. doi: 10.2196/jmir.5692. PubMed PMID: 27806926; PubMed PMCID: PMCPMC5295827.

58. Hamine S, Gerth-Guyette E, Faulx D, Green BB, Ginsburg AS. Impact of mHealth chronic disease management on treatment adherence and patient outcomes: a systematic review. J Med Internet Res. 2015;17:e52. doi: 10.2196/jmir.3951. PubMed PMID: 25803266; PubMed PMCID: PMCPMC4376208. 